\title{
VIABLE OPTIONS FOR FERTILITY PRESERVATION IN BREAST CANCER PATIENTS: A FOCUS ON LATIN AMERICA
}

\author{
Matteo Lambertini ${ }^{1,2 \S^{*}}$, Oranite Goldrat ${ }^{3 \S}$, Regina Barragan-Carrillo ${ }^{4}$, Giulia Viglietti ${ }^{1}$,

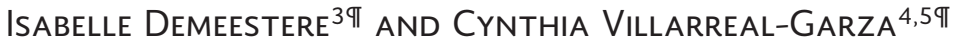

${ }^{1}$ Breast Cancer Translational Research Laboratory and ${ }^{2}$ Breast Data Centre, Department of Medicine, Institut Jules Bordet and I'Université Libre de Bruxelles (ULB); ${ }^{3}$ Fertility Clinic, Research Laboratory on Human Reproduction, Erasme Hospital, and l'Université Libre de Bruxelles, Brussels, Belgium; ${ }^{4}$ Breast Cancer Centre, Zambrano Hellion Hospital, Tecnologico de Monterrey, Monterrey, NL, Mexico; ${ }^{5}$ Breast Cancer Research Department, Instituto Nacional de Cancerología, Mexico City, Mexico

\begin{abstract}
Thanks to the improved survival outcomes observed in recent years, a growing attention has been given to the quality of life issues faced by young women with breast cancer such as fertility preservation and concerns related to future pregnancies. However, several challenges remain for young women with breast cancer considering undergoing fertility preservation strategies. Further specific issues on this regard should be taken into account in Latin America, where patients and physicians face particular barriers that hinder the routine adoption of this practice. Hence, further efforts are needed to overcome these deficiencies and improve the correct referral of breast cancer patients to fertility preservation strategies.

The aim of the present review is to focus on the risk of anticancer treatment-related premature ovarian failure and infertility in young breast cancer patients, to summarize the current knowledge on the available options for fertility preservation, and to discuss the safety issues of pregnancy in breast cancer survivors. Furthermore, this review aims to highlight the specific clinical challenges in this field encountered by healthcare providers and young breast cancer patients from Latin American countries. (REV INVES CLIN. 2017;69:103-13)
\end{abstract}

Key words: Breast cancer. Fertility preservation. Premature ovarian failure. Latin America. Young women.

\section{INTRODUCTION}

Among young women of reproductive age, breast cancer is the most commonly diagnosed malignancy ${ }^{1}$. In Latin America, the mean age at diagnosis of breast cancer is approximately 10 years younger than in the United States of America (USA) ${ }^{2}$. In this region, the proportion of breast cancers arising in premenopausal women on the total incident cases is substantially higher (average $47.3 \%$ ) as compared to more developed countries (average $18.5 \%)^{3}$. Furthermore, while in the USA $5 \%$ of the new breast cancer cases are diagnosed in patients under the age of 40, in Latin America the rate of breast cancer in young women reaches $10-15 \%^{2}$. Thus, breast cancer

\section{Corresponding author:}

*Matteo Lambertini

Institut Jules Bordet, and l'Université Libre de Bruxelles (ULB)

Boulevard de Waterloo 121

1000 Bruxelles, Belgium

E-mail: matteo.lambertini85@gmail.com

\author{
$\S$ Authors \\ "Coauthors \\ Received for publication: 14-02-2017 \\ Approved for publication: 20-02-2017
}


among young Latin American patients represents a growing burden throughout the region.

Personalized approaches are needed to manage the specific age-associated needs of young women with breast cancer in terms of both optimal anticancer treatments and other crucial quality of life issues ${ }^{4}$. Anticancer therapies can be associated with important long-term negative consequences such as the risk of developing impairment of fertility and premature ovarian failure (POF) ${ }^{5}$. As shown in the "Helping Ourselves, Helping Others: The Young Women's Breast Cancer Study" conducted in the USA, approximately half of the young women with newly diagnosed breast cancer are worried about the possible treatment-related loss of fertility and ovarian function' ${ }^{6}$. These concerns can be associated with important psychosocial distress and might impact the decision on the proposed anticancer treatments ${ }^{6}$. Similar findings have also been observed in young patients from more resource-limited societies. A recent survey conducted in two referral centers in Mexico showed that, at the time of diagnosis, $44 \%$ of young breast cancer patients expressed some level of concern about the risk of treatment-related infertility ${ }^{7}$. This study reported that the only significant predictor of infertility concern was the desire for having children preceding diagnosis ${ }^{7}$.

Current guidelines on fertility preservation in cancer patients highlight the importance of informing all patients diagnosed during their reproductive years about the possible risk of treatment-related POF and infertility, and then to discuss the different available options for fertility preservation with interested patients ${ }^{8,9}$. Oncofertility counseling should now be considered as part of routine clinical practice and represents a key moment during the first medical consultation with newly diagnosed young patients ${ }^{10,11}$. However, not all patients and their treating physicians are adequately informed on this regard. In the Mexican survey, only $31 \%$ of young breast cancer patients recalled having received information from their providers regarding possible infertility following cancer therapy ${ }^{7}$. As shown in another recent survey conducted among physicians participating at the $3^{\text {rd }}$ ESO-ESMO Breast Cancer in Young Women Conference (BCY3), 36\% of the responders have never consulted the available international guidelines on fertility preservation in cancer patients ${ }^{12}$. Hence, further educational initiatives and distribution of information are needed to improve knowledge around this topic and adherence to available guidelines.

The aim of the present review is to focus on the risk of anticancer treatment-related infertility and POF in young breast cancer patients, to summarize the current knowledge on the available options for fertility preservation, and to discuss the safety issues of pregnancy in breast cancer survivors. Furthermore, this review aims to highlight the specific clinical challenges in this field faced by physicians and patients from Latin American countries.

\section{IMPACT OF BREAST CANCER ON FUTURE PREGNANCIES AND FERTILITY POTENTIAL}

Despite the fact that approximately half of the young women with newly diagnosed early-stage breast cancer desire to have a pregnancy ${ }^{13}$, less than $10 \%$ manage to subsequently become pregnant ${ }^{14}$. It is well known that female cancer survivors have significantly lower pregnancy rates as compared to the general population of a similar age hazard ratio [HR]: 0.61; $95 \%$ confidence intervals [CI]: 0.58-0.64) ${ }^{15}$. Furthermore, among cancer survivors, young women with breast cancer have the lowest pregnancy rate, with a $67 \%$ reduced chance of future pregnancies as compared to the general population (HR: $0.33 ; 95 \% \mathrm{Cl}$ : $0.27-0.39)^{15}$. There are two possible main explanations for these findings: the concerns of providers and patients of a possible negative impact of pregnancy on the recurrence of breast cancer, and the gonadotoxic impact of the anticancer therapies required to treat this type of disease.

Recent surveys have confirmed the skepticism of some physicians on the safety of pregnancy in breast cancer survivors. A recent Italian survey showed that $46 \%$ of the surveyed oncologists believed that pregnancy affects the prognosis of young women with breast cancer, and $49 \%$ supported the statement that an increase in estrogen levels during pregnancy might stimulate the growth of hidden cancer cells ${ }^{16}$. Similarly, $30 \%$ of the physicians responding to the $\mathrm{BCY} 3$ survey agreed or were neutral on the statement that pregnancy in breast cancer survivors may increase the risk of recurrence ${ }^{12}$. 
Similar findings have been recently reported in Mexico, with only $25 \%$ of surveyed healthcare providers considering pregnancy after breast cancer safe (unpublished data). However, current data support the safety of pregnancy after breast cancer diagnosis. It has been shown that a pregnancy in breast cancer survivors does not have a negative prognostic impact, regardless of the hormone receptor status of the tumor. In the meta-analysis by Azim, et al., including 14 retrospective control-matched studies with 1,244 cases and 18,145 controls, breast cancer survivors with a pregnancy during follow-up showed a $41 \%$ reduced risk of death compared to patients who did not become pregnant (pooled relative risk [PRR]: 0.59; $95 \% \mathrm{Cl}: 0.50-0.70)^{17}$. When correcting for the "healthy mother effect", a 15\% non-significant reduction in the risk of death for women who subsequently became pregnant was also observed (PRR: 0.85; $95 \% \mathrm{Cl}: 0.53-1.35)^{17}$. A subsequent large multicenter retrospective cohort study adjusting for the "healthy mother effect" confirmed the safety of pregnancy in breast cancer survivors and even specifically in those with endocrine-sensitive disease ${ }^{18}$. In this study, 333 pregnant patients and 874 matched non-pregnant patients were included. No difference in disease-free survival (DFS) was observed between pregnant and non-pregnant patients both in the estrogen receptorpositive cohort (HR: $0.91 ; 95 \% \mathrm{Cl}: 0.67-1.24 ; \mathrm{p}=$ 0.55 ) and in the estrogen receptor-negative group (HR: $0.75 ; 95 \% \mathrm{Cl}: 0.51-1.08 ; \mathrm{p}=0.12$ ). Patients in the pregnant cohort had a better overall survival (OS) than the non-pregnant group (HR: $0.72 ; 95 \% \mathrm{Cl}$ : $0.54-0.97 ; p=0.03)$; no interaction according to estrogen receptor status was observed $(p=0.11)^{18}$. A more recent meta-analysis including 19 studies with 1,829 cases and 21,907 controls confirmed the lack of negative prognostic impact of pregnancy following breast cancer ${ }^{19}$. On the contrary, pregnant patients showed a significantly reduced risk of death compared to non-pregnant patients (HR: $0.63 ; 95 \% \mathrm{Cl}$ : 0.51-0.79). A subgroup analysis accounting for the "healthy mother effect" reported similar results (HR: $0.65 ; 95 \% \mathrm{Cl}: 0.52-0.81)^{19}$. Hence, taking into account all these findings, after adequate treatment and follow-up, pregnancy in breast cancer survivors, including in those with hormone receptor-positive disease, should not be discouraged anymore ${ }^{20}$.

A second important explanation for the low pregnancy rate in breast cancer survivors is the negative impact of anticancer treatments on patients' gonadal function. The key factors associated with treatment-related POF risk in breast cancer patients include administration of chemotherapy and use of endocrine therapy ${ }^{5}$, and, even more importantly, age of the patient and anti-Müllerian hormone (AMH) level at the time of diagnosis ${ }^{21,22}$. The major limitation in counseling young patients on the likelihood of developing treatment-related POF is the fact that menstrual function assessed at different time-points after the end of chemotherapy was considered a surrogate indicator of gonadal activity ${ }^{23}$. In fact, it is known that resumption of menstruation is not always associated with recovered ovarian function, and women previously exposed to chemotherapy with cyclic menstrual activity may still have diminished ovarian reserve and reduced fertility potential $^{24}$. Taking into account this limitation during oncofertility counseling, all young women with breast cancer should be advised that a higher risk of developing treatment-related POF is associated with older age (closer to the natural age of menopause) at the time of treatment, the use of alkylating agents (particularly cyclophosphamide), and the need for prolonged adjuvant endocrine therapy ${ }^{5}$. In the $\mathrm{Na}$ tional Surgical Adjuvant Breast and Bowel Project (NSABP) B-30 trial comparing three different adjuvant chemotherapy regimens (sequential doxorubicin [A] and cyclophosphamide [C] followed by docetaxel $[T ; A C \rightarrow T], A T$, and $T A C$ ), amenorrhea rates by treatment arm were assessed with standardized questionnaires at baseline and at follow-up visits every six months ${ }^{25}$. A different percentage of patients experienced at least 24 months of amenorrhea according to their age at the time of treatment, ranging from $61 \%$ in women under the age of 40 to $100 \%$ in patients older than 50 years. Amenorrhea rates at 12 months after the start of therapy were significantly different between treatment arms: $37.9 \%$ for AT, $57.7 \%$ for $T A C$, and $69.8 \%$ for $A C \rightarrow T$ $(p<0.001)$. The addition of tamoxifen increased the risk of treatment-related amenorrhea; patients who received AT chemotherapy without tamoxifen showed the lowest rate of amenorrhea (20-25\% across the two-year period of observation) ${ }^{25}$. Recent data have confirmed the intermediate risk of treatment-related POF with the use of anthracyclinebased or anthracycline- and taxane-based regimens (ranging from 43 to 57\%) with both standard administration and dose-dense schedules ${ }^{26}$. These data 
further highlight the need to counsel all young patients at risk of treatment-related POF and infertility, and to refer those interested in fertility preserving procedures to fertility clinics as soon as possible before starting anticancer treatments ${ }^{8,9}$.

\section{AVAILABLE OPTIONS FOR FERTILITY PRESERVATION}

In breast cancer patients, the available options for fertility preservation include temporary ovarian suppression with gonadotropin-releasing hormone agonists ( $\mathrm{GnRHa}$ ) during chemotherapy, embryo/oocyte cryopreservation, and cryopreservation of ovarian tissue. Specific pro and contra and country availability are presented in table 1 ; these should be discussed and made clear during oncofertility counseling (Fig. 1).

Table 2 describes the more suitable candidates for the different fertility preserving procedures among young patients with breast cancer.

\section{Temporary ovarian suppression with GnRHa during chemotherapy}

Temporary ovarian suppression with GnRHa during chemotherapy has been studied as a strategy to preserve gonadal function during the administration of cytotoxic therapy. Its major advantages are the wide availability, the lack of delay in the initiation of anticancer treatments, and no requirement for a surgical procedure. However, due to the previous conflicting results on its efficacy, the protective role of temporary ovarian suppression with GnRHa during chemotherapy has been largely debated over the past years ${ }^{27-30}$, and this strategy was considered experimental by the 2013 international guidelines on fertility preservation in cancer patients ${ }^{8,9}$. Nevertheless, several recent important updates on this topic have supported the protective role of this strategy in young women with breast cancer undergoing (neo)adjuvant chemotherapy ${ }^{31}$.

The two largest phase III trials investigating the protective role of temporary ovarian suppression with GnRHa during chemotherapy randomly assigned young breast cancer patients with early-stage disease to receive (neo)adjuvant chemotherapy plus concurrent GnRHa or cytotoxic therapy alone ${ }^{32,33}$. All the 257 patients included in the POEMS-SWOG S0230 trial had hormone receptor-negative disease ${ }^{32}$, while $80 \%$ of the 281 women enrolled in the PROMISEGIM6 study had hormone receptor-positive tumors ${ }^{34}$. Both studies showed consistent results in terms of the protective gonadal effect of this strategy; as compared to cytotoxic therapy alone, the concurrent administration of GnRHa and chemotherapy showed to significantly reduce the risk of developing treatment-induced POF, from 22 to $8 \%$ in the POEMSSWOG S0230 trial odds ratio [OR]: $0.30 ; 95 \% \mathrm{Cl}$ : $0.09-0.97 ; p=0.04)^{32}$ and from 25.9 to $8.9 \%$ in the PROMISE-GIM6 study (OR: 0.28; $95 \% \mathrm{Cl}$ : 0.14-0.59; $\mathrm{p}<0.001)^{34}$. More patients treated with GnRHa during chemotherapy than those receiving cytotoxic therapy alone had a subsequent pregnancy; however, the result was significant in the POEMS-SWOG S0230 trial (22 vs. 12 women; OR: 2.45 ; $95 \% \mathrm{Cl}$ : 1.09-5.51; $\mathrm{p}=0.03)^{32}$ and not in the PROMISE-GIM6 study ( $8 \mathrm{vs.}$ 3 women; age-adjusted HR: 2.40; $95 \% \mathrm{Cl}$ : 0.62-9.22; $\mathrm{p}=0.20)^{33}$.

When the results of all the 12 randomized studies assessing the role of temporary ovarian suppression with GnRHa during chemotherapy were pooled together, a significant reduction in the risk of developing treatment-induced POF was observed with the use of this strategy (OR: 0.36; 95\% Cl: 0.23-0.57; $<<0.001)^{35}$. Moreover, although the numbers remain low, with only five studies reporting this outcome, the metaanalysis showed a significantly higher number of patients with a subsequent pregnancy (33 vs. 19 women) when adding GnRHa to chemotherapy (OR: $1.83 ; 95 \%$ $\mathrm{Cl}: 1.02-3.28 ; \mathrm{p}=0.041$ ). Despite only three studies having reported data on the potential safety of administering GnRHa concurrently with chemotherapy, no apparent negative impact on DFS was observed (HR: $1.00 ; 95 \% \mathrm{Cl}: 0.49-2.04 ; \mathrm{p}=0.939)^{35}$.

Taking into account these findings, recent guidelines have acknowledged the clinical utility of temporary ovarian suppression with GnRHa during chemotherapy in breast cancer patients interested in preserving ovarian function and/or fertility 4,36 . The cost of the procedure for six months of treatment during (neo) adjuvant chemotherapy is approximately 1,000 dollars for each patient. In Italy, the Italian Ministry of Health has recently granted coverage for this strategy to all young breast cancer patients ${ }^{36}$. Due to the 
Table 1. Main characteristics of the different strategies for fertility preservation

\begin{tabular}{|c|c|c|c|}
\hline Type of strategy & Main results & Pro & Contra \\
\hline $\begin{array}{l}\text { Temporary ovarian } \\
\text { suppression with GnRHa } \\
\text { during chemotherapy }\end{array}$ & $\begin{array}{l}\text { - Reduction in the risk of } \\
\text { developing treatment- } \\
\text { induced POF (OR; } 0.36 ; 95 \% \\
\text { Cl: 0.23-0.57; } p<0.001 \text { ) } \\
\text { - Higher number of patients } \\
\text { with a subsequent } \\
\text { pregnancy ( } 33 \text { vs. } 19 \\
\text { women; OR: } 1.83 ; 95 \% \mathrm{Cl} \text { : } \\
\text { 1.02-3.28; } \mathrm{p}=0.041) \\
\text { - No apparent negative } \\
\text { impact on survival (HR: } \\
\text { 1.00; 95\% Cl: } 0.49-2.04 ; \mathrm{p} \\
\text { = 0.939) }\end{array}$ & $\begin{array}{l}\text { - No need for controlled } \\
\text { ovarian hyperstimulation } \\
\text { - No delay in the initiation } \\
\text { of anticancer therapies } \\
\text { - No surgery required } \\
\text { - Widely available } \\
\text { - Limited cost }\end{array}$ & $\begin{array}{l}\text { - No data on long-term } \\
\text { preservation of ovarian } \\
\text { function (age at } \\
\text { menopause) } \\
\text { - Limited data on fertility } \\
\text { preservation potential } \\
\text { - Limited data on long-term } \\
\text { survival outcomes }\end{array}$ \\
\hline $\begin{array}{l}\text { Embryo/oocyte } \\
\text { cryopreservation }\end{array}$ & $\begin{array}{l}\text { - Variable live birth rates } \\
\text { according to age at the time } \\
\text { of the procedure (data from } \\
\text { the infertile non-oncologic } \\
\text { population): } 22.7 \% \text { for } \\
\text { patients }<34 \text { years, } 18.1 \% \\
\text { for women aged } 35-39, \text { and } \\
<10 \% \text { for women }>40 \\
\text { years } \\
\text { - Pregnancy rate of } 51.5 \% \text { in } \\
\text { a series of } 33 \text { breast cancer } \\
\text { patients } \\
\text { - No apparent negative } \\
\text { impact on survival in breast } \\
\text { cancer patients (HR: } 0.77 ; \\
95 \% \text { Cl: } 0.28-2.13 ; \mathrm{p}= \\
0.61 \text { ) }\end{array}$ & $\begin{array}{l}\text { - Most reliable results on } \\
\text { fertility preservation } \\
\text { potential (in infertile } \\
\text { non-oncologic women) } \\
\text { - Minor surgery required } \\
\text { - Good availability }\end{array}$ & $\begin{array}{l}\text { - No preservation of ovarian } \\
\text { function } \\
\text { - Need for controlled ovarian } \\
\text { hyperstimulation } \\
\text { - Possible delay in the } \\
\text { initiation of anticancer } \\
\text { therapies } \\
\text { - Limited efficacy and safety } \\
\text { data in cancer patients } \\
\text { - Need for a specialized } \\
\text { fertility preservation facility } \\
\text { - High cost* }\end{array}$ \\
\hline $\begin{array}{l}\text { Cryopreservation of } \\
\text { ovarian tissue }\end{array}$ & $\begin{array}{l}\text { - Successful recovery of } \\
\text { ovarian function expected } \\
\text { within 3-6 months } \\
\text { - Possible sustained longevity } \\
\text { of ovarian function } \\
\text { - Almost } 100 \text { babies born } \\
\text { worldwide } \\
\text { - Live birth rate estimated } \\
\text { around } 30 \%\end{array}$ & $\begin{array}{l}\text { - No need for controlled } \\
\text { ovarian hyperstimulation } \\
\text { - Minimal or no delay in the } \\
\text { initiation of anticancer } \\
\text { therapies } \\
\text { - Preservation of both } \\
\text { fertility and ovarian } \\
\text { function }\end{array}$ & $\begin{array}{l}\text { - Need for } 2 \text { surgical } \\
\text { procedures } \\
\text { - Limited efficacy and safety } \\
\text { data in cancer patients } \\
\text { - Need for a specialized } \\
\text { fertility preservation facility } \\
\text { - Risk of reintroduction of } \\
\text { malignant cells at the time } \\
\text { of transplantation }\end{array}$ \\
\hline
\end{tabular}

*May vary by country.

$\mathrm{Cl}$ : confidence intervals; GnRHa: gonadotropin-releasing hormone agonists; HR: hazard ratio; OR: odds ratio; POF: premature ovarian failure.

lower cost as compared to cryopreservation procedures, temporary ovarian suppression with $\mathrm{GnRHa}$ during chemotherapy may also become an option in Latin America. However, this should not be regarded as an alternative of care, and embryo/oocyte cryopreservation should be always considered as the first strategy to be discussed with patients willing to preserve fertility (Fig. 1). Final results from the MOMMY study, an ongoing individual patient data meta-analysis investigating the role of temporary ovarian suppression with GnRHa during chemotherapy in breast cancer patients (PROSPERO registration number: CRD42014015638) ${ }^{20}$, are awaited to provide final evidence regarding the efficacy and safety of this procedure.

\section{Embryo/oocyte cryopreservation}

Embryo/oocyte cryopreservation are standard strategies for fertility preservation in female cancer patients ${ }^{8,9}$. They require controlled ovarian hyperstimulation $(\mathrm{COH})$, which induces supra-physiological estradiol levels along with the development of several follicles ${ }^{37}$. In infertile women without cancer, embryo cryopreservation following $\mathrm{COH}$ demonstrated the most reliable results in terms of subsequent 
Figure 1. Oncofertility counseling and indications for the different strategies for fertility preservation in young breast cancer patients. $\mathrm{COH}$ : controlled ovarian hyperstimulation; CT: chemotherapy; GnRHa: gonadotropin-releasing hormone agonists; POF: premature ovarian failure.

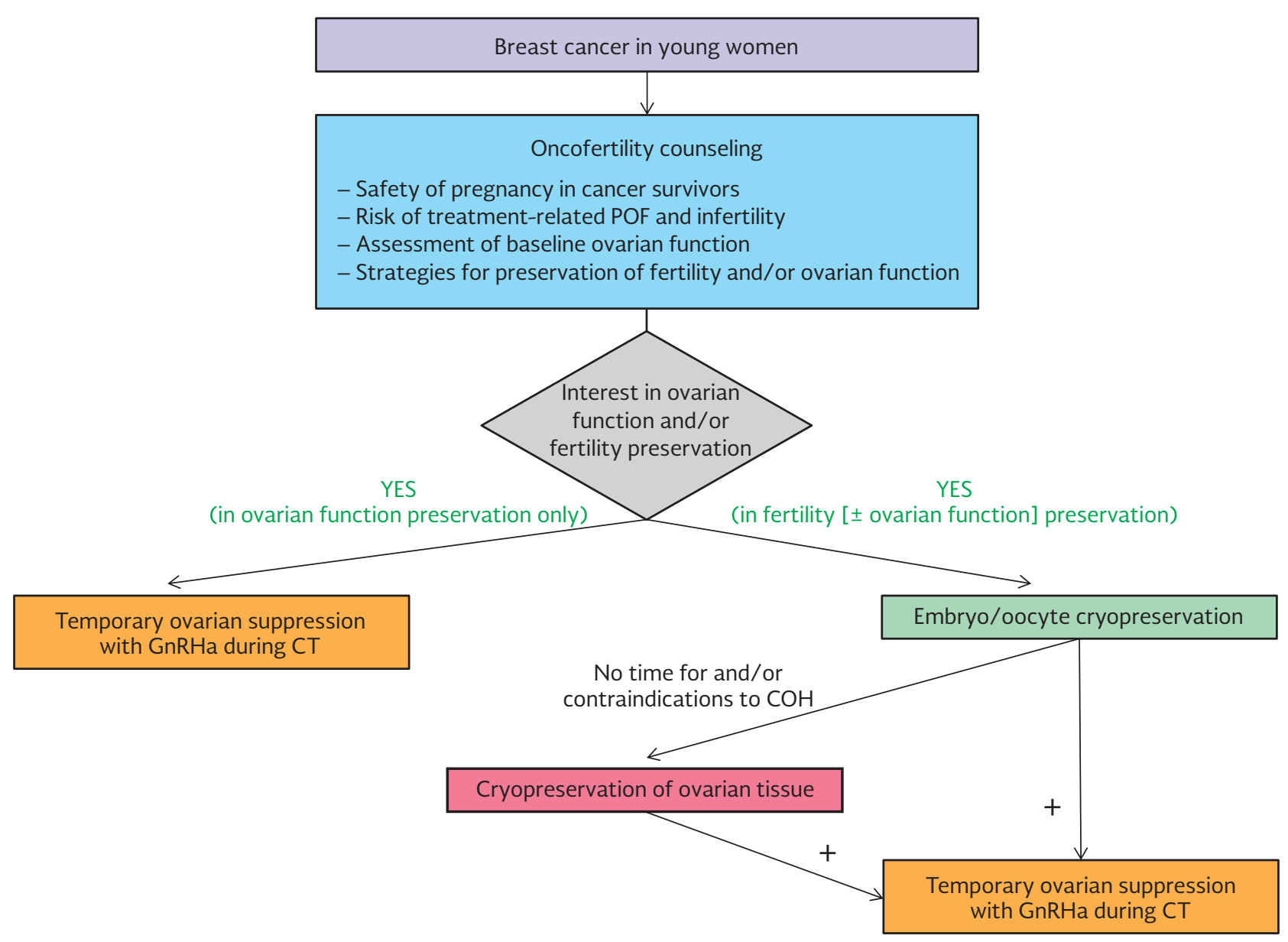

pregnancies. The success of embryo cryopreservation is strongly dependent on the patient's age at the time of oocyte retrieval and fertilization ${ }^{37}$. Using this procedure, the live birth rates according to the 2012 European Society of Human Reproduction and Embryology (ESHRE) were $22.7 \%$ for patients younger than 34 years, $18.1 \%$ for women aged $35-39$, and less than $10 \%$ for women older than 40 years ${ }^{38}$. In experienced centers, similar results can be obtained after oocyte cryopreservation ${ }^{39,40}$.

In breast cancer patients, $\mathrm{COH}$ protocols have been adjusted in order to avoid the possible detrimental impact of high estradiol levels on cancer cell proliferation using concomitant administration of letrozole (an aromatase inhibitor) ${ }^{41,42}$ or tamoxifen (an estrogen receptor modulator) ${ }^{43-45}$.

\section{Letrozole-associated controlled ovarian hyperstimulation}

In the protocol developed by Oktay, et al., letrozoleassociated $\mathrm{COH}$ cycles were initiated either in a "standard" or "random-start" protocol according to the patient's menstrual cycle phase and the urgency to start chemotherapy ${ }^{41,42}$. In the "standard" proto$\mathrm{col}$, letrozole was initiated on the second or third day of menstruation, followed two days later by gonadotropin administration. A GnRHa was administered as soon as one follicle reached $14 \mathrm{~mm}$ or estradiol levels rose to $250 \mathrm{pg} / \mathrm{ml}$, to avoid premature luteinization. In the "random start" protocol, letrozole, gonadotropins, and GnRHa were initiated at the same time throughout $\mathrm{COH}$ until ovulation triggering ${ }^{37}$. 
Table 2. The best candidates for the different strategies for fertility preservation among young patients with breast cancer

\begin{tabular}{|l|l|}
\hline Type of strategy & Best candidates \\
\hline $\begin{array}{l}\text { Temporary ovarian } \\
\text { suppression with GnRHa } \\
\text { during chemotherapy }\end{array}$ & $\begin{array}{l}\text { - Patients interested in ovarian function preservation only (no interest in fertility } \\
\text { preservation) } \\
\text { - Patients interested in fertility preservation (age }<38 \text { to } 40 \text { years) but*: } \\
\text { Following embryo/oocyte cryopreservation, and/or } \\
\text { No access to embryo/oocyte cryopreservation }\end{array}$ \\
\hline $\begin{array}{l}\text { Embryo/oocyte } \\
\text { cryopreservation }\end{array}$ & $\begin{array}{l}\text { Patients interested in fertility preservation with: } \\
\text { Age }<38 \text { to } 40 \text { years, and } \\
\text { Good ovarian reserve, and }\end{array}$ \\
\hline $\begin{array}{l}\text { Cryopreservation of } \\
\text { ovarian tissue }\end{array}$ & - Patients aged $<36$ years interested in fertility preservation with high risk of premature \\
& ovarian insufficiency: \\
& Who cannot delay treatment initiation, and/or \\
& With contraindication to controlled ovarian hyperstimulation \\
\hline
\end{tabular}

"The use of temporary ovarian suppression with GnRHa during chemotherapy is not an alternative to embryo/oocyte cryopreservation. ${ }^{\dagger}$ Despite the use of random-start protocols for controlled ovarian stimulation, 2 weeks are usually required.

GnRHa: gonadotropin-releasing hormone agonists.

Ovulation triggering was commonly induced by human chorionic gonadotropin or GnRHa in case of ovarian hyperstimulation syndrome risk ${ }^{37}$. When estradiol levels remained high after oocyte retrieval, letrozole was administered again until it declined to $<50 \mathrm{pg} /$ $\mathrm{ml}$. Recently, Goldrat, et al. have shown high progesterone levels during early luteal phase following this protocol ${ }^{46}$. As progesterone may be as important as estradiol on tumorigenesis ${ }^{47}$, the authors recommended triggering ovulation with GnRHa in all breast cancer patients, regardless of ovarian hyperstimulation syndrome risk, and avoiding administration of letrozole after oocyte retrieval ${ }^{46}$.

Conflicting results have been reported regarding the number of mature oocytes yielded in letrozole-associated $\mathrm{COH}$ compared to patients undergoing $\mathrm{COH}$ without letrozole ${ }^{48,49}$. Nonetheless, in 2015, Oktay, et al. reported the success rate of oocytes/embryos cryopreservation using letrozole-associated $\mathrm{COH}$ in the largest breast cancer cohort reported to date ${ }^{45}$. Thirty-three breast cancer survivors who had undergone embryo cryopreservation with letrozole-associated $\mathrm{COH}$ returned for 40 frozen embryo transfers (either to herself or a gestational carrier), which resulted in 18 deliveries of 25 healthy babies. The livebirth rate $(18 / 40,45 \%)$ was similar to the general infertile population ${ }^{45}$. Furthermore, the same group has shown reassuring results regarding the safety of performing $\mathrm{COH}^{50}$. They compared the relapse rate in a cohort of 119 breast cancer patients who underwent letrozole-associated $\mathrm{COH}$ for fertility preservation with 152 matched patients who did not undergo fertility preserving procedures. All characteristics were comparable between groups except for lower lymph node involvement in the group undergoing embryo cryopreservation ( 34 vs. $48 \% ; p=0.02$ ). After a mean follow-up of more than five years, no survival difference was observed, with a relapse rate of 5.0 and $5.5 \%$ in patients who underwent or not $\mathrm{COH}$, respectively $(p=0.86)$, with a HR for recurrence after embryo cryopreservation of $0.56(95 \% \mathrm{Cl}$ : $0.17-1.9 ; p=0.36)^{50}$.

\section{Tamoxifen-associated ovarian hyperstimulation}

Tamoxifen represents an alternative to letrozole in $\mathrm{COH}$ for embryo/oocyte cryopreservation in breast cancer patients ${ }^{37}$. It is usually combined with gonadotropins at doses ranging from 20 to $60 \mathrm{mg} /$ day until the day of ovulation trigger ${ }^{44,51}$. The number of mature oocytes and embryos obtained with tamoxifen-associated $\mathrm{COH}$ were similar to results achieved after $\mathrm{COH}$ without tamoxifen in endocrine receptor-negative breast cancer patients (12.65 \pm 8.04 vs. $10.22 \pm 6.08 ; p=0.183$, and $8.51 \pm 6.57$ vs. $6.41 \pm 4.64 ; p=0.265$, respectively $)^{44}$. However, there are some safety issues related to the use of tamoxifen-associated $\mathrm{COH}$, mainly due to the delay in achieving steady state for tamoxifen and its bioactive metabolite endoxifen (approximately two months $)^{52}$. After daily administration of $60 \mathrm{mg}$ of tamoxifen in four patients who underwent fertility preservation $\mathrm{COH}$, Balkenende, et al. showed a great variability in the serum levels of the drug and its 
metabolite, achieving insufficient concentration in one of the patients ${ }^{52}$.

\section{In vitro maturation}

In some cases, $\mathrm{COH}$ is not a feasible option for fertility preservation, mainly due to time constraints as well as oncologists' and/or patients' safety concerns on the risk of breast cancer recurrence. Immature oocytes collected at any phase of the menstrual cycle followed by in vitro maturation (IVM) may hence be a viable option. Maturation and fertilization rates with this technique vary between $50-70 \%$ and $70-80 \%$, respectively ${ }^{53,54}$. However, implantation, clinical pregnancy, and live birth rates as well as miscarriage rates have been described mainly for non-oncologic patients with polycystic ovary syndrome. A recent study comparing the pregnancy outcomes after IVM procedure or standard in vitro fertilization showed that IVM was less efficient after fresh embryo transfer (live birth rates of 18 vs. $31 \%$; $p=0.021)^{55}$. However, frozen-thawed embryo transfers showed similar results between groups, suggesting that IVM might be an interesting alternative option for fertility preservation in breast cancer patients ${ }^{55}$.

\section{Cryopreservation of ovarian tissue}

In this technique, ovarian tissue from either ovarian biopsies or the whole ovary is collected by laparoscopy, and small fragments are cryopreserved for a possible future auto-transplantation to restore ovarian function and fertility. Immature oocytes can also be collected ex vivo on the ovarian tissue and cryopreserved after IVM during the procedure when performed before gonadotoxic treatments. The main advantages of this procedure are avoidance of delay in chemotherapy initiation and hormone exposure associated to $\mathrm{COH}$.

The technique is still considered as experimental, but almost 100 babies were born worldwide after ovarian tissue transplantation at an orthotopic site, and live birth rates have been estimated around $30 \%{ }^{56,57}$. Van Der Ven, et al. have recently reported pregnancies of 16 grafted patients ${ }^{56}$. Among them, five were breast cancer survivors aged between 28-38 years at the time of ovarian tissue cryopreservation. All these patients became pregnant and delivered following ovarian tissue transplantation ${ }^{56}$. Nevertheless, it should be kept in mind that the success rate depends mainly on the age and ovarian reserve (hence follicular density) at the time of tissue cryopreservation. Young patients diagnosed with breast cancer are often already in their 30 s and might subsequently have a lower chance of pregnancy following ovarian tissue grafting ${ }^{58}$.

Some safety issues are still under investigation, especially regarding the possibility of reintroducing malignant cells during a transplantation procedure ${ }^{20}$. Luyckx, et al. analyzed 13 thawed ovarian tissues from advanced breast cancer patients using histology, immunohistochemistry, xenografting to mice, and quantitative polymerase chain reaction for gene expression of mammaglobin 2 (MGB2) ${ }^{59}$. They found no microscopic cancer cells and xenograft results were also reassuring; however, MGB2 expression was positive in four out of 13 cases $^{59}$. Other studies assessed the usefulness of molecular markers for the detection of residual disease in the ovarian tissue of breast cancer patients. Using PCR technique, mammaglobin 1 (MGB1), gross cystic disease fluid protein 15, and small breast epithelial mucin showed the highest predictive values in the detection of micro-metastases in ovarian tissue of breast cancer ${ }^{60-63}$. Hoekman, et al. detected positive MGB1 expression in ovarian tissue in one out of three patients with breast cancer and sentinel lymph node involvement ${ }^{61}$. Results are reassuring overall, but further studies are needed to confirm the clinical relevance of the detection of these markers to adequately counsel patients.

\section{ACCESS TO FERTILITY PRESERVATION STRATEGIES IN LATIN AMERICA}

Although oncofertility counseling should now be considered an essential component in the management of young women with breast cancer, in Latin America efforts are predominantly dedicated to improve cancer survival rates. Hence, fertility preservation issues are often neglected. Only a minority of patients receives information about treatment-related POF and infertility by their physicians, and a limited number of them are ultimately referred to a fertility specialist $^{7,64}$. Some of the particular challenges that can explain the lack of routine practice of fertility preservation procedures in Latin America include inequitable distribution of cancer centers and specialists, lack of public healthcare coverage for supportive care, and significant socioeconomic gaps. 
The availability of specialized fertility preservation centers in Latin America is limited, and these units are usually concentrated in major cities and located in tertiary care facilities. The latest edition of the Latin American Registry for Assisted Reproductive Technologies reported that only 158 assisted reproduction facilities are available in Argentina, Bolivia, Brazil, Chile, Colombia, Ecuador, Guatemala, Mexico, Nicaragua, Panama, Paraguay, Peru, Dominican Republic, Uruguay, and Venezuela65. This number is far behind the available centers in more developed countries such as the USA, where over 440 clinics provide service to patients seeking to overcome infertility ${ }^{66}$. Hence, fertility units are out of reach for a large proportion of patients in Latin America.

The low access to fertility preserving procedures in Latin America is also explained by the fact that these options are not covered either by the governments or by private health insurers ${ }^{64}$. This represents a direct and often unreachable out of pocket expense for patients, particularly in limited resource settings with income inequities. As an example, in a web-based survey conducted in Mexico among 241 oncology healthcare providers, the most prevailing factor that hindered the referral of cancer patients to fertility preservation was its high cost (unpublished data). In the previously mentioned survey in Mexican patients regarding their fertility concerns in two referral centers in Mexico with access to public health services, only $3 \%$ of patients considered themselves able to afford extra expenses beyond oncologic treatment ${ }^{7}$. As a consequence, in such countries where fertility preservation depends on the individual capacity to afford its coverage, the access to these procedures will likely remain low.

Another important reason explaining the low referral rates of cancer patients to fertility clinics in Latin America is the physician's inconsistent disclosure of infertility risks. There are several possible explanations for these findings: the high proportion of advanced breast cancer cases in young patients, the concern of physicians of delaying cancer treatment if fertility preservation is pursued, the lack of knowledge on the effects of systemic therapy on fertility, and the concern about the effect of pregnancy on breast cancer prognosis. In the aforementioned Mexican survey, for example, a shocking $75 \%$ of healthcare providers considered pregnancy unsafe after breast cancer diagnosis (unpublished data).

\section{FUTURE PERSPECTIVES}

Thanks to the improved survival outcomes observed in recent years, a growing attention has been given to the quality of life issues faced by young women with breast cancer such as fertility preservation and concerns related to future pregnancies. However, several challenges remain for young women with breast cancer considering undergoing fertility preserving procedures. Further, specific issues should be considered on this regard for Latin American patients and physicians. Hence, additional efforts are needed in the coming years to overcome these deficiencies and improve the correct referral of breast cancer patients to fertility preservation strategies.

First, it is crucial to improve the equality in access to different strategies for fertility preservation for patients from all countries. The implementation of a federal policy recognizing the right to start a family as a human right can provide universal access to assisted reproductive technologies. This is the case of Argentina, where the number of assisted reproductive cycles per population has increased in the general population since the approval in 2013 of the law number 26.862 ("Acceso integral a los procedimientos y tecnicas medico-asistenciales de reproduccion medicamente asistida"). Furthermore, the promotion of local alliances between oncology and reproductive centers could potentially increase cross-specialty communication and referrals, as well as diminish costs. Likewise, the integration of dedicated programs for young breast cancer patients has also changed the current breast cancer treatment paradigm to not only treat and cure the disease, but to also give weight to the quality of life of young survivors. As an example, the implementation of the "PYNK" initiative in Canada ${ }^{67}$ and the "Joven y Fuerte" program in Mexico ${ }^{68}$ has indeed increased the number of timely referrals to fertility preservation procedures.

Second, despite increasing awareness about the different strategies for fertility preservation, there is lack of data on patient preferences and needs towards the different strategies for fertility preservation ${ }^{69}$. Data from the western world suggest that despite the great proportion of women concerned about fertility at the time of diagnosis, a limited percentage of patients (approximately 10\%) decided to take special steps to lessen their risk of infertility with the use of fertility preserving procedures ${ }^{6}$. In the Mexican study, less than $1 \%$ pursued fertility preserving 
procedures; different reasons might explain this low proportion such as limited access due to high costs and unawareness of the infertility risks associated with oncologic treatment ${ }^{7}$. Prospective efforts, such as the Italian PREFER study (ClinicalTrials.gov Identifier: NCT02895165), the HOHO study in the USA ${ }^{6}$, the PYNK program in Canada ${ }^{67}$, and the Mexican Joven y Fuerte Program ${ }^{68}$, among others, are currently ongoing to try to better understand the preferences and needs of patients towards the different strategies. This information is crucial to improve the quality of oncofertility counseling, but also from a public health perspective for better allocation of resources.

Third, further research efforts are needed to generate more solid data to counsel BRCA-mutated women on the safety of pregnancy after breast cancer, the impact of anticancer treatments on their ovarian function, and the feasibility of the different strategies for fertility preservation ${ }^{70}$. This is also important to be taken into account in women from Latin American countries where the prevalence of $B R C A$ mutations (ranging from 1.2 to $4.9 \%$ ) is very similar to that of the non-Hispanic population in the USA ${ }^{71}$. Specific issues should be considered in the field of fertility preservation in cancer patients for BRCA carriers. In fact, it has been hypothesized that mutations in the BRCA genes may be associated with primary occult ovarian insufficiency that might potentially lead to subsequently lower reproductive potential, increased risk of treatment-related gonadotoxicity, and low response to fertility treatments ${ }^{72}$. However, very limited clinical data exist in this regard in BRCA-mutated breast cancer patients, and further research in this field should be considered a priority.

\section{ACKNOWLEDGEMENTS}

Matteo Lambertini acknowledges the support from the European Society for Medical Oncology (ESMO) for a Translational Research Fellowship at Institut Jules Bordet, Brussels, Belgium.

\section{REFERENCES}

1. DeSantis CE, Fedewa SA, Goding Sauer A, Kramer JL, Smith RA, Jemal A. Breast cancer statistics, 2015: Convergence of incidence rates between black and white women. CA Cancer J Clin. 2016;66:31-42.

2. Villarreal-Garza C, Aguila C, Magallanes-Hoyos MC, et al. Breast cancer in young women in Latin America: an unmet, growing burden. Oncologist. 2013;18(Suppl):26-34.
3. Ghiasvand R, Adami H-O, Harirchi I, Akrami R, Zendehdel K Higher incidence of premenopausal breast cancer in less developed countries; myth or truth? BMC Cancer. 2014;14:343.

4. Paluch-Shimon S, Pagani O, Partridge $\mathrm{AH}$, et al. Second international consensus guidelines for breast cancer in young women (BCY2). Breast. 2016;26:87-99

5. Poggio F, Levaggi A, Lambertini M. Chemotherapy-induced premature ovarian failure and its prevention in premenopausal breast cancer patients. Expert Rev Quality Life Cancer Care. 2016;1:5-7.

6. Ruddy KJ, Gelber SI, Tamimi RM, et al. Prospective study of fertility concerns and preservation strategies in young women with breast cancer. J Clin Oncol. 2014;32:1151-6

7. Villarreal-Garza C, Martinez-Cannon BA, Platas A, et al. Fertility concerns among breast cancer patients in Mexico. Breast 2017:33:71-5

8. Loren AW, Mangu PB, Beck LN, et al. Fertility preservation for patients with cancer: American Society of Clinical Oncology clinical practice guideline update. J Clin Oncol. 2013;31:2500-10.

9. Peccatori FA, Azim HA Jr, Orecchia R, et al. Cancer, pregnancy and fertility: ESMO Clinical Practice Guidelines for diagnosis, treatment and follow-up. Ann Oncol. 2013;24(Suppl 6):vi160-70.

10. Lambertini M, Anserini P, Levaggi A, Poggio F, Del Mastro L. Fertility counseling of young breast cancer patients. J Thorac Dis. 2013;5(Suppl 1):S68-80

11. Woodruff TK, Smith K, Gradishar W. Oncologists' role in patient fertility care: A call to action. JAMA Oncol. 2016;2(2):171-2.

12. Lambertini M, Di Maio M, Pagani $O$, et al. A survey on physicians' knowledge, practice and attitudes on fertility and pregnancy issues in young breast cancer patients. BCC 2017 - St. Gallen Conference, Vienna. March 2017. [Abstract P189].

13. Letourneau JM, Ebbel EE, Katz PP, et al. Pretreatment fertility counseling and fertility preservation improve quality of life in reproductive age women with cancer. Cancer. 2012;118:1710-7.

14. Litton JK. Breast cancer and fertility. Curr Treat Options Oncol. 2012:13:137-45

15. Stensheim H, Cvancarova M, Møller B, Fosså SD. Pregnancy after adolescent and adult cancer: a population-based matched cohort study. Int J Cancer. 2011;129:1225-36.

16. Biglia N, Torrisi R, D'Alonzo M, Codacci Pisanelli G, Rota S, Peccatori FA. Attitudes on fertility issues in breast cancer patients: an Italian survey. Gynecol Endocrinol. 2015;31:458-64.

17. Azim HA Jr, Santoro L, Pavlidis N, et al. Safety of pregnancy following breast cancer diagnosis: a meta-analysis of 14 studies. Eur J Cancer. 2011;47:74-83

18. Azim HA Jr, Kroman N, Paesmans M, et al. Prognostic impact of pregnancy after breast cancer according to estrogen receptor status: a multicenter retrospective study. J Clin Oncol. 2013;31:73-9.

19. Hartman EK, Eslick GD. The prognosis of women diagnosed with breast cancer before, during and after pregnancy: a meta-analysis. Breast Cancer Res Treat. 2016;160:347-60.

20. Lambertini M, Del Mastro L, Pescio MC, et al. Cancer and fertility preservation: international recommendations from an expert meeting. BMC Med. 2016;14:1.

21. Barnabei A, Strigari L, Marchetti P, et al. Predicting ovarian activity in women affected by early breast cancer: A meta-analysisbased nomogram. Oncologist. 2015;20:1111-8.

22. Bozza C, Puglisi F, Lambertini M, Osa E-O, Manno M, Del Mastro L. Anti-Mullerian hormone: determination of ovarian reserve in early breast cancer patients. Endocr Relat Cancer. 2014;21:R51-65.

23. Lee SJ, Schover LR, Partridge AH, et al. American Society of Clinical Oncology recommendations on fertility preservation in cancer patients. J Clin Oncol. 2006;24:2917-31.

24. Reh $\mathrm{A}$, Oktem O, Oktay $\mathrm{K}$. Impact of breast cancer chemotherapy on ovarian reserve: a prospective observational analysis by menstrual history and ovarian reserve markers. Fertil Steril. 2008;90:1635-9

25. Ganz PA, Land SR, Geyer CE Jr, et al. Menstrual history and quality-of-life outcomes in women with node-positive breast cancer treated with adjuvant therapy on the NSABP B-30 trial. J Clin Oncol. 2011;29:1110-16.

26. Lambertini M, Ceppi M, Cognetti F, et al. Dose-dense adjuvant chemotherapy in premenopausal breast cancer patients: A pooled analysis of the MIG1 and GIM2 phase III studies. Eur ] Cancer. 2017;71:34-42

27. Turner NH, Partridge A, Sanna G, Di Leo A, Biganzoli L. Utility of gonadotropin-releasing hormone agonists for fertility preservation in young breast cancer patients: the benefit remains uncertain. Ann Oncol. 2013;24:2224-35.

28. Lambertini M, Poggio F, Levaggi A, Del Mastro L. Protecting ovaries during chemotherapy through gonad suppression: A systematic review and meta-analysis. Obstet Gynecol. 2015;126:901. 
29. Del Mastro L, Lambertini M. Temporary ovarian suppression with gonadotropin-releasing hormone agonist during chemotherapy for fertility preservation: Toward the end of the debate? Oncologist. 2015;20:1233-5.

30. Lambertini M, Peccatori FA, Moore HCF, Del Mastro L. Reply to the letter to the editor "Can ovarian suppression with gonadotropin releasing hormone analogs $(\mathrm{GnRHa})$ preserve fertility in cancer patients?" by Rodriguez-Wallberg et al. Ann Oncol. 2016;27:548-9.

31. Lambertini M, Poggio F, Vaglica M, Blondeaux E, Del Mastro L. News on the medical treatment of young women with earlystage HER2-negative breast cancer. Expert Opin Pharmacother. 2016;17:1643-55

32. Moore HCF, Unger JM, Phillips K-A, et al. Goserelin for ovarian protection during breast-cancer adjuvant chemotherapy. N Engl J Med. 2015;372:923-32.

33. Lambertini M, Boni L, Michelotti A, et al. Ovarian suppression with triptorelin during adjuvant breast cancer chemotherapy and long-term ovarian function, pregnancies, and disease-free survival: A randomized clinical trial. JAMA. 2015;314:2632-40.

34. Del Mastro L, Boni L, Michelotti A, et al. Effect of the gonadotropinreleasing hormone analogue triptorelin on the occurrence of chemotherapy-induced early menopause in premenopausal women with breast cancer: a randomized trial. JAMA. 2011;306:269-76.

35. Lambertini M, Ceppi M, Poggio F, et al. Ovarian suppression using luteinizing hormone-releasing hormone agonists during chemotherapy to preserve ovarian function and fertility of breast cancer patients: a meta-analysis of randomized studies. Ann Oncol. 2015;26:2408-19.

36. Lambertini M, Cinquini M, Moschetti I, et al. Temporary ovarian suppression during chemotherapy to preserve ovarian function and fertility in breast cancer patients: A GRADE approach for evidence evaluation and recommendations by the Italian Association of Medical Oncology. Eur J Cancer. 2017;71:25-33.

37. Lambertini M, Pescio MC, Viglietti G, et al. Methods of controlled ovarian stimulation for embryo/oocyte cryopreservation in breast cancer patients. Expert Rev Quality Life Cancer Care. 2017;2:47-59.

38. European IVF-Monitoring Consortium (EIM) for the European Society of Human Reproduction and Embryology (ESHRE), Calhaz-Jorge C, de Geyter C, Kupka MS, et al. Assisted reproductive technology in Europe, 2012: results generated from European registers by ESHRE. Hum Reprod. 2016;31:1638-52.

39. Rienzi L, Cobo A, Paffoni $A$, et al. Consistent and predictable delivery rates after oocyte vitrification: an observational longitudinal cohort multicentric study. Hum Reprod. 2012;27:1606-12.

40. Bianchi V, Lappi M, Bonu MA, Borini A. Oocyte slow freezing using a 0.2-0.3 M sucrose concentration protocol: is it really the time to trash the cryopreservation machine? Fertil Steril. 2012;97:1101-7.

41. Oktay K, Hourvitz A, Sahin G, et al. Letrozole reduces estrogen and gonadotropin exposure in women with breast cancer undergoing ovarian stimulation before chemotherapy. J Clin Endocrinol Metab. 2006;91:3885-90

42. Azim AA, Costantini-Ferrando M, Oktay K. Safety of fertility preservation by ovarian stimulation with letrozole and gonadotropins in patients with breast cancer: a prospective controlled study. J Clin Oncol. 2008;26:2630-5.

43. Oktay K, Buyuk E, Davis O, Yermakova I, Veeck L, Rosenwaks Z. Fertility preservation in breast cancer patients: IVF and embryo cryopreservation after ovarian stimulation with tamoxifen. Hum Reprod. 2003;18:90-5.

44. Meirow D, Raanani H, Maman E, et al. Tamoxifen co-administration during controlled ovarian hyperstimulation for in vitro fertilization in breast cancer patients increases the safety of fertility-preservation treatment strategies. Fertil Steril. 2014;102:488-95.e3.

45. Oktay K, Turan V, Bedoschi G, Pacheco FS, Moy F. Fertility preservation success subsequent to concurrent aromatase inhibitor treatment and ovarian stimulation in women with breast cancer. J Clin Oncol. 2015;33:2424-9.

46. Goldrat O, Gervy C, Englert Y, Delbaere A, Demeestere I. Progesterone levels in letrozole associated controlled ovarian stimulation for fertility preservation in breast cancer patients. Hum Reprod. 2015;30:2184-9.

47. Brisken C. Progesterone signalling in breast cancer: a neglected hormone coming into the limelight. Nat Rev Cancer. 2013;13:385-96.

48. Revelli A, Porcu E, Levi Setti PE, Delle Piane L, Merlo DF, Anserini $P$. Is letrozole needed for controlled ovarian stimulation in patients with estrogen receptor-positive breast cancer? Gynecol Endocrinol. 2013;29:993-6.

49. Pereira N, Hancock K, Cordeiro CN, Lekovich JP, Schattman GL, Rosenwaks Z. Comparison of ovarian stimulation response in patients with breast cancer undergoing ovarian stimulation with letrozole and gonadotropins to patients undergoing ovarian stimulation with gonadotropins alone for elective cryopreservation of oocytest. Gynecol Endocrinol. 2016;32:823-6.

50. Kim J, Turan V, Oktay K. Long-term safety of letrozole and gonadotropin stimulation for fertility preservation in women with breast cancer. J Clin Endocrinol Metab. 2016;101:1364-71.

51. Oktay K, Buyuk E, Libertella N, Akar M, Rosenwaks Z. Fertility preservation in breast cancer patients: a prospective controlled comparison of ovarian stimulation with tamoxifen and letrozole for embryo cryopreservation. J Clin Oncol. 2005;23:4347-53.

52. Balkenende EM, Dahhan T, Linn SC, Jager NG, Beijnen JH, Goddijn M. A prospective case series of women with estrogen receptor-positive breast cancer: levels of tamoxifen metabolites in controlled ovarian stimulation with high-dose tamoxifen. Hum Reprod. 2013;28:953-9.

53. Shalom-Paz E, Almog B, Shehata F, et al. Fertility preservation for breast-cancer patients using IVM followed by oocyte or embryo vitrification. Reprod Biomed Online. 2010;21:566-71.

54. Chian R-C, Uzelac PS, Nargund G. In vitro maturation of human immature oocytes for fertility preservation. Fertil Steril. 2013;99:1173-81.

55. Walls ML, Hunter T, Ryan JP, Keelan JA, Nathan E, Hart RJ. In vitro maturation as an alternative to standard in vitro fertilization for patients diagnosed with polycystic ovaries: a comparative analysis of fresh, frozen and cumulative cycle outcomes. Hum Reprod. 2015;30:88-96.

56. Van der Ven $H$, Liebenthron J, Beckmann $M$, et al. Ninety-five orthotopic transplantations in 74 women of ovarian tissue after cytotoxic treatment in a fertility preservation network: tissue activity, pregnancy and delivery rates. Hum Reprod. 2016;31:2031-41.

57. Jensen AK, Macklon KT, Fedder J, Ernst E, Humaidan P, Andersen $C Y .86$ successful births and 9 ongoing pregnancies worldwide in women transplanted with frozen-thawed ovarian tissue focus on birth and perinatal outcome in 40 of these children. J Assist Reprod Genet. 2016. [Epub ahead of print].

58. Imbert R, Moffa F, Tsepelidis S, et al. Safety and usefulness of cryopreservation of ovarian tissue to preserve fertility: a 12 year retrospective analysis. Hum Reprod. 2014;29:1931-40.

59. Luyckx V, Durant JF, Camboni A, et al. Is transplantation of cryopreserved ovarian tissue from patients with advanced-stage breast cancer safe? A pilot study. J Assist Reprod Genet. 2013;30:1289-99.

60. Bockstaele L, Boulenouar S, Van Den Steen G, et al. Evaluation of quantitative polymerase chain reaction markers for the detection of breast cancer cells in ovarian tissue stored for fertility preservation. Fertil Steril. 2015;104:410-17.e4.

61. Hoekman EJ, Smit VT, Fleming TP, Louwe LA, Fleuren GJ, Hilders CG. Searching for metastases in ovarian tissue before autotransplantation: a tailor-made approach. Fertil Steril. 2015;103:469-77.

62. Rodríguez-Iglesias B, Novella-Maestre E, Herraiz S, Díaz-García C, Pellicer N, Pellicer A. New methods to improve the safety assessment of cryopreserved ovarian tissue for fertility preservation in breast cancer patients. Fertil Steril. 2015;104:1493-502.e1-2.

63. Peters IT, Hilders CG, Sier CF, et al. Identification of cell-surface markers for detecting breast cancer cells in ovarian tissue. Arch Gynecol Obstet. 2016;294:385-93.

64. Dyer KE, Quinn GP. Cancer and fertility preservation in Puerto Rico: A qualitative study of healthcare provider perceptions. Support Care Cancer. 2016;24:3353-60

65. Zegers-Hochschild F, Schwarze JE, Crosby JA, Musri C, Urbina MT. Assisted reproductive techniques in Latin America: The Latin American registry, 2013. J Bras Reprod Assist. 2016;20:49-58.

66. Ishihara O, Adamson GD, Dyer S, et al. International committee for monitoring assisted reproductive technologies: World report on assisted reproductive technologies, 2007. Fertil Steril. 2015;103:402-13.e11.

67. Cohen L, Hamer J, Helwig C, et al. Formal evaluation of PYNK: Breast cancer program for young women-the patient perspective. Curr Oncol Tor Ont. 2016;23:e102-8.

68. Villarreal-Garza C, Platas A, Martinez-Cannon BA, et al. Information needs and internet use of breast cancer survivors in Mexico. Breast J. 2016. [Epub ahead of print].

69. Lambertini M, Pinto AC, Del Mastro L. Fertility issues in young breast cancer patients: what women want. J Thorac Dis. 2014;6:584-8.

70. Lambertini M, Del Mastro L. Fertility preservation in BRCA-mutated breast cancer patients. Breast Cancer Management. 2016;5:61-8.

71. Dutil J, Golubeva VA, Pacheco-Torres AL, Diaz-Zabala HJ, Matta $\mathrm{JL}$, Monteiro AN. The spectrum of BRCA1 and BRCA2 alleles in Latin America and the Caribbean: a clinical perspective. Breast Cancer Res Treat. 2015;154:441-53.

72. Rodriguez-Wallberg KA, Oktay K. Fertility preservation and pregnancy in women with and without BRCA mutation-positive breast cancer. Oncologist. 2012;17:1409-17. 